\title{
Occupational Hazards in Prosthodontic Practice: A Review
}

Ghimire $\mathrm{B}^{1}$

${ }^{1}$ Assistant Professor, Department of Prosthodontics, Kantipur Dental College and Hospital, Basundhara, Kathmandu, Nepal.

\begin{abstract}
Every occupation has its own hazards and risks, prosthodontic practice is not an exception. With the evolution in materials and instrumentations, dental professionals have become prone to diverse risks of occupational hazards. These risks include exposure to physical and chemical agents, dental materials, infectious environment, inappropriate working pattern and psychosocial stress. The potential health risks of prosthodontic practice, use of dental materials and its impact in health have not been explored much. In this review, hazards and risks associated with prosthodontic practice have been highlighted and preventive measures to reduce the risks among professionals have been discussed.
\end{abstract}

Key words: Chemical; Hazard, Knowledge; Occupational; Prosthodontics

\section{Introduction}

$\mathrm{O}$ ccupational hazards can be defined as a risk to a person usually arising out of employment. ${ }^{1}$ It can also refer to a work material, substance, process or situation that predisposes or itself causes accidents or diseases. Occupational health risks are present in every profession, including prosthodontic practice. Despite these hazards, we cannot refrain from providing patient care. Adequate knowledge of occupational hazards and sufficient information pertaining to their prevention will assure safety of Prosthodontists and the team as well as contribute in providing quality care to patients. Although identification of the risks to general dental practice has been explored, the potential health risks to prosthodontic practice, use of dental materials and its impact in health have

\section{Conflict of Interest: No}

\author{
*Corresponding Author \\ Dr. Barsha Ghimire \\ Assistant Professor, Department of Prosthodontics, \\ Kantipur Dental College and Hospital, Kathmandu, \\ Basundhara, Nepal. \\ Kantipur Dental College and Hospital \\ E-mail:b28barsha@gmail.com
}

not been explored sufficiently. In this review, we have explored the preventive and therapeutic measures to minimize these risks.

\section{Materials and Methods}

Online literature search was done in Google Scholar and PubMed with key words occupational hazards, dental materials risk in practice, biological hazards, ergonomic hazards, legal hazards to assess all the essential studies and reviews. Only English based dental literature published from January 1985 to March 2020 were considered for this review. Obtained information regarding prosthodontic health hazards and risks were scripted in a contextual manner.

\section{Occupational Hazards in Prosthodontic Practice}

The field of dentistry is not an exception for an exposure to occupational hazards. Prosthodontists are exposed to many health related risk while providing dental care to patients. Prosthodontists and related auxiliary employees are usually exposed to a number of occupationalhazards. The potential risk ofirritant chemicals, inhalation of vapors, dust particles, 
injury from high-speed rotary instrument and inflammable materials does exist. Moreover, contact with restorative and prosthetic dental materials of widely varied composition such as metals, resin-based synthetic polymers and dental ceramics needs outsourcing from the clinic to the laboratories, thereby widening the circle of potentially infectious agents. ${ }^{2}$ Occupational hazards in prosthodontic practice may be broadly classified as Physical hazard, Visionary hazard, Acoustic hazard, Chemical hazard, Microbial hazard, Ergonomics hazard, Sociopsychological hazard and Legal hazard. ${ }^{1}$

\section{Various Occupational Hazards In}

\section{Prosthodontic}

\section{Physical Hazard:}

Physical hazard related to prosthodontics practice includes direct physical trauma, burns, damage to skin. The direct physical trauma includes accidental skin cuts and abrasions due to the usage of blunt or broken instruments or high-speed projectile during trimming and polishing denture. According to a study done by Siew $\mathrm{C}$ et al., percutaneous injuries occurred at a yearly rate of $3.4 \%$ among dentists. Among specialists, endodontists had highest prevalence of $5.5 \%$ while prosthodontists had second highest prevalence rate of $4.5 \% .{ }^{3}$ Caution while using sharp instruments and avoiding use of blunt and broken instruments help minimize such risk. The second most common injury in a prosthodontic clinic or laboratory is burns from Bunsen burners, spirit lamps, blow torches, careless handling of hot instruments, wax splashes, spontaneous ignitions of inflammable materials and use of solders and molten metals. Judicious use of hot instrument, accessible fire extinguisher, regular practice of routine fire drill help minimizes these risks.

\section{Visionary Hazard}

Mechanical, thermal or chemical factor can lead to visionary damage. High speed cutting tools can generate high velocity projectile at 39 meters/secs, being very hot and sharp, it can cause mild irritation through corneal abrasion, ulceration to complete blindness. ${ }^{4,5}$ Chemical injury can lead to corneal ulceration to complete blindness. Splashing of spirits can lead to pain and corneal irritations. Monomer of Methyl Methacrylate (MMA), pumice containing lime or quartz causes corneal abrasions. Polymerization of resin using blue curling light of 400-500nm wavelength, can have detrimental effect in cornea and retina with maximum ocular risk at about $440 \mathrm{~nm}$. When the blue light

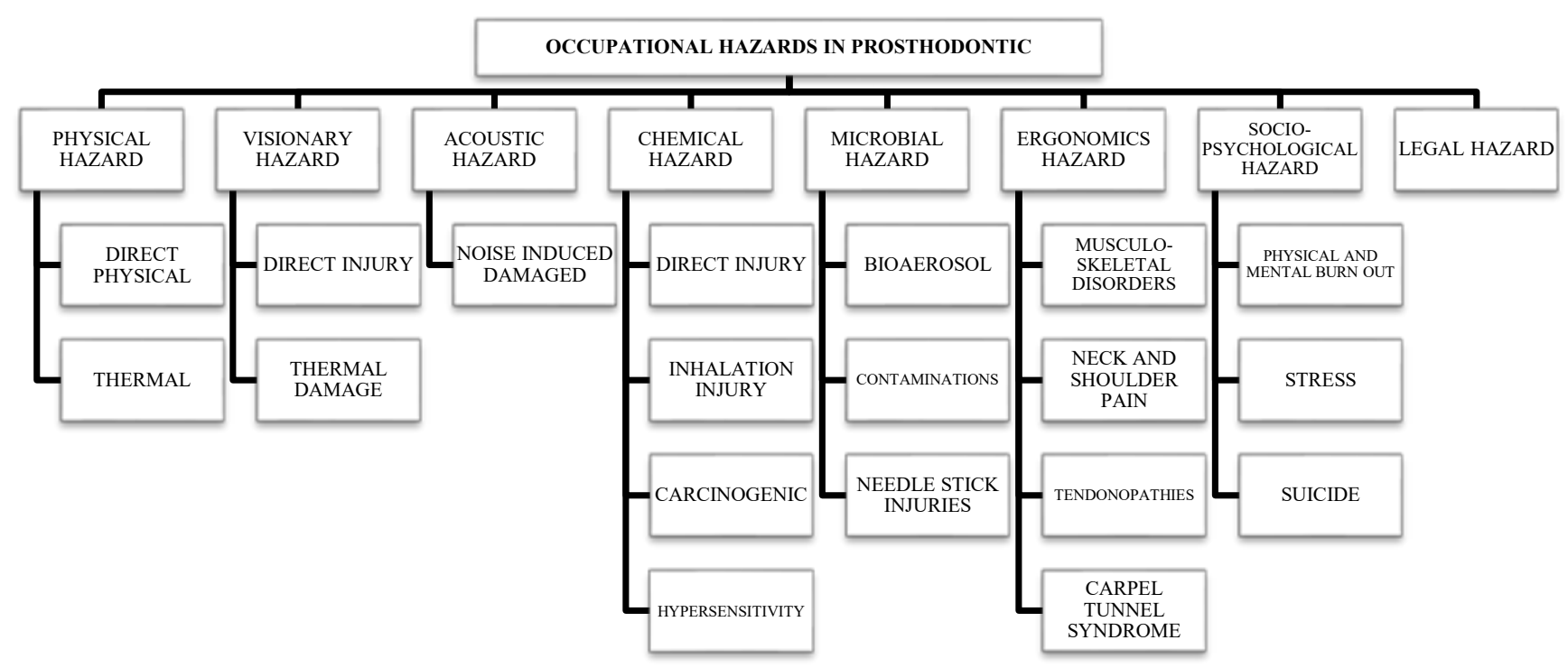

Figure 1: Various Causes of Occupational Hazards in Prosthodontics 
strikes the retina, they inhibit the formation of cytochrome-C-oxidase, which transports oxygen to photoreceptors and other retinal cells. Without cytochrome-C-oxidase, degeneration of retina occurs. ${ }^{6}$ An orange shield is used with the curing equipment that adequately filters blue light between $350 \mathrm{~nm}$ to $500 \mathrm{~nm}$. Apart from this, blue light filtering spectacle with side shields help to protect against reflectance and scatter.

\section{Acoustic Hazard}

Prosthodontists are exposed to different levels of noise, which may lead to hearing disorders. High-speed hand piece, high velocity suction, vibrators and other mixing devices can be the potential hazard to auditory system. According to OSHA, exposure to $85 \mathrm{~dB}$ of noise, known as an exposure action value, for more than eight hours per day, can result in permanent hearing loss. ${ }^{7}$ Upgrading to modern dental equipment with lower noise level or use of ear plug may help minimal risk of hearing loss.

\section{Chemical Hazard:}

Prosthodontists deal-with new materials every day. Dealing with various materials increases the risk of chemical hazards. Use of variety of materials ranging from latex gloves to wax and ceramic to alloy, exposes prosthodontists to their adversities. Alloys, resin polymers, dental cements, ceramics, waxes, eugenol-containing materials, elastomeric impression materials can cause dermatitis. Ingested or inhalation of component of such chemicals can lead to various inflammation, immunological reactions and even carcinogenesis over their prolonged exposure. $^{8}$

\section{Metal Alloys}

Ceramic materials are generally regarded as inert, but dust particles from these materials during handling, manipulating, adjusting and finishing the restorations represent a potential problem for the laboratory and clinical personnel. Metals, especially cobalt-chromium, nickel, and gold alloys are used for metal ceramic restorations and removable partial denture frameworks. Dental technicians are exposed to respirable metal fumes and dusts during trimming and polishing of cast dental restorations. Metallic fumes can cause pneumoconiosis. A study reported that 53 of 70 dental technicians were affected by pneumoconiosis which could be caused by dust from the processing of dental materials. ${ }^{9}$ Exposure to beryllium vapor or particles is associated with contact dermatitis and chronic granulomatous lung disease, known as chronic beryllium disease (CBD) and also increase risk of lung carcinoma and osteosarcoma. ${ }^{10}$ Use of Nickel and chromium bears risk of development of Nasal and lung carcinoma respectively. National Institute for Occupational Safety and Health (NIOSH) recommend exposure limit of $0.05 \mathrm{mg} / \mathrm{m}^{3}$ for such dust particles. Inhalation of dust containing free silica or silicon dioxide particles in ceramic laboratories leads to silicosis. ${ }^{11}$ Dental products such as polymer and resins used in restorative dentistry may act as allergens manifesting as allergic contact dermatitis during clinical use.

\section{Methylmethacrylate}

Polymethyl methacrylate resin posed threat to prosthodontists and technicians during packing, trimming and finishing the prosthesis. Vaporized Methyl methacrylate enters body by inhalation or from direct contact through skin. Methyl methacrylate vapor in the air at the level of $125 \mathrm{ppm}$ may cause teary eyes, sore throat and coughing. ${ }^{12}$ Direct skin contact can cause itching, burning, redness, swelling and cracking of the skin, tingling, numbness or whitening of the fingers. Guideline regarding legal exposure limits includes California Division of Occupational Safety and Health, which has adopted a permissible limit for the amount of Methyl methacrylate that is 100 parts of MMA per million parts of air which is equal to 410 milligram of MMA per cubic meter of air (410 $\left.\mathrm{mg} / \mathrm{m}^{3}\right)$. Average exposure for any 8 -hour work 
shift is 100 ppm or less. ${ }^{13}$ Methods to reduce the exposure should be adopted.

\section{Hydrofluoric Acid (Hf)}

Since the introduction of glass-based ceramics and discovery of the benefits of adhesive cementation in dentistry, hydrofluoric acid (HF) started to be used to condition restorative and prosthetic devices. HF is highly hazardous chemical due to its toxicity, corrosiveness, and high reactivity. Contact with it can produce acute severe burn injury, while chronic exposure may lead to skeletal fluorosis that can be fatal. ${ }^{14,15}$

\section{Hypersensitivity}

Gloves are most commonly used during treatments by a dentist as one of the protective barriers. Latex gloves are usually dusted with corn starch powder. Inhalation of glove powder is capable of inducing type 1 hypersensitivity responses but the most common type of allergic reaction is the delayed hypersensitivity or allergic contact dermatitis. Latex allergy and glove dermatitis were reported in $9 \%$ and $22 \%$ of dental personnel respectively in a dental school in Australia. ${ }^{16}$ Skin manifestation may be reduced by substitution with vinyl and nitryl gloves. Exposure to materials like methacrylate vapor and acrylic dust can induce occupational asthma, conjunctival symptoms and allergic contact dermatitis. It was recommended to use a local exhaust ventilation system, which significantly reduced the peak concentration of these compounds. ${ }^{17}$

\section{Radiation Hazard}

Dental personnel are exposed to ionizing as well as a non-ionizing type of radiations. Ionizing radiation is a major risk factor for cancer. Almost most dental offices and clinics have $\mathrm{x}$-ray machines that are in frequent use, the exposure of these radiations has a major drawback. Protocols such as standing behind protective barriers and also use radiation monitoring badges must be considered. Direct radiation injury has been greatly eliminated by improvements in equipment and methods and protective measures. ${ }^{18}$ However, the potential effects of whole-body doses remain of concern, with secondary radiation scattered from bones in the patient's head now representing the greatest source of radiation received by professional. ${ }^{19}$ Precautions, like wearing lead aprons and lead layered walls, must be used.

\section{Microbial Hazard}

During many dental procedures, the chief portals of entry of infection are epidermis of hands, oral or nasal cavities and conjunctival epithelium. The spread of infection is not only from contaminated aerosols but also from contaminated instrument and impressions. In order to overcome the infection, a thorough knowledge about the infection control, mode of transmission and safety measures is necessary. Sterilization and disinfection are of utmost important to minimize this risk.

\section{Bioaerosol}

Dental drills cause the formation of aerosol and splatter commonly contaminated with bacteria, viruses, fungi and blood. Aerosols are liquid and solid particles $(<50 \mu \mathrm{m}$ diameter) suspended in air for protracted periods. Splatter is a mixture of air, water and/or solid substances $(50 \mu \mathrm{m}$ to several millimeters diameter) which are a health risk to the dental team. ${ }^{20}$ Proximity of patient and prosthodontist during the procedure increases the risk of transmission of respiratory aerosol. This increases the risk of transmission of respiratory borne diseases including tuberculosis, influenza etc. Recently, the Novel coronavirus (COVID19) has been a global pandemic posing challenge to health professions. The COVID-19 measures around $120 \mathrm{~nm}(0.12 \mu \mathrm{m})$ and aerosol particle sizes range from 3-100 nm. Due to its high infectivity and unpredictable clinical course, suspension of routine dental care and proper use of Personal Protective Equipment (PPE), social distancing and frequent hand washing has been recommended. The use of a FFP3 respirator 
offers a filtration rate of $99 \%$ of all particles measuring up to $0.6 \mu \mathrm{m}$ and is helpful to protect staffs against COVID-19. ${ }^{21}$ Recommendations to attenuate the environmental contamination and optimize infection control against SARSCoV-2 is through quaternary ammonium compounds or isopropyl alcohol. ${ }^{22}$ High-speed instrumentations pose a significant risk of biological hazard via the generation of splatters and aerosols during procedure which can access to the mucosa or conjunctiva risking infection to health personnel. Measures to minimize aerosol generated infection should be adopted. Use of protective barriers helps minimize the risk.

\section{Contamination}

Handling of contaminated instruments or dental material bears significant risk of infection to the prosthodontics and auxiliary employee as well as cross contamination to subsequent patients. ${ }^{23}$ Contaminated dental unit waterlines (DUWL), handpieces, saliva ejectors and suctions as well as other devices attached to air and waterlines are also potential sources. ${ }^{24}$ Decontamination of DUWL includes the state-of-the-art method using ozone. The integration of the use of ozone into a dental unit extends a system of disinfection and sterilization for DUWL into the clinical management and patient arena. Based on the guidelines provided by the Centers for Disease Control and Prevention (CDC) and American Dental Association (ADA) all dental prosthesis, impressions, occlusion rims, temporary prosthesis or wax bite registrations should be thoroughly cleaned, disinfected with an Environmental Protection Agency (EPA) registered hospital disinfectant and thoroughly rinsed before being handled to the laboratory. Sterilization of instruments is utmost in prevention. ${ }^{25}$

\section{Needle Stick Injurie}

Prosthodontics instrumentations and procedures demand the use of sharp instruments and use of high-speed drills. Accidental injury can risk infection with blood borne pathogens including Human Immunodeficiency Virus (HIV) or Hepatitis (HEP B \& C). This not only risk prosthodontics but also to auxiliary staffs. Similarly, improper sterilization can risk cross contamination to subsequent patients. Routine application of universal precaution and effective sterilization of instruments as per OSHA guideline reduces such risk to employee. Use of post exposure prophylaxis will increase safety windows if exposed. The Occupational Safety and Health Administration (OSHA) has published Controlling Occupational Exposure to Bloodborne Pathogens in Dentistry. These OSHA guidelines are designed to protect the employee, not the patient. The OSHA bloodborne pathogen standard is a comprehensive rule that sets forth specific requirements. OSHA guidelines are designed to prevent the transmission of blood-borne diseases to employees. It includes requirements for an exposure control plan, exposure control precautions, laundry procedures, mandatory hepatitis B vaccinations, housekeeping standards, and waste disposal regulations. ${ }^{26}$

\section{Ergonomics Hazard}

Prosthodontists are at high risk of neck and back problems due to the limited work area and impaired vision associated with the oral cavity. These working restrictions frequently cause them to assume stressful body positions to achieve good access and visibility inside the oral cavity which result in awkward positions over long periods of time; which in turn result in back problems. The symptoms include low back pain, stiffness, and sciatica with neurological features such as tingling, paresthesia, and muscle weakness. ${ }^{27}$ Repetitive and forceful maneuver during prosthodontic work along with use of vibrating tools cause fluid accumulation and inflammation of tendons inside tendon sheaths compromising the median nerve in carpel canal producing carpel tunnel syndrome presenting as pain, tingling and numbness in the lateral 
aspect of hand. ${ }^{28}$ Similarly, repeated grasping or twisting with hand during procedure causes tendinopathies producing pain in thumb and wrist pain (De-Quervain's diseases) or ring and little fingers pain (Guyon's syndrome). Prevention of musculoskeletal problems includes maintaining correct body posture while treating patients, taking adequate rest, doing some physical exercises.

\section{Sociopsychological Hazard}

Physical and mental burn out and stress, dissatisfaction to treatment, uncooperative patients over workload, constant drive for technical perfection, underuse of skills, challenging environment, and low self-esteem with hesitant prognosis produce stress. Good communication between the doctor and the patient has a positive influence. Stressors such as failing to meet personal expectations, seeing more patients for financial reasons may lead to physical and mental burnout. Failure to cope with stress may misguide one toward substance abuse and anxiety or depression. Breaking the large task into small ones, application of relaxation, hypnosis and desensitization technique helps in stress management. Strategies to cope with stress and burnout were identified as active coping, planning, religion, sports, forgetting about work, interaction with people, and acceptance. ${ }^{29}$

\section{Legal Hazard}

In every country there are relevant statutes and regulations which apply to the practice of dentistry. To help assure a safe work environment in dental treatment, the hazard awareness and prevention of legal risks should be made known to all clinical workers of the dental hospital. Understanding of medico legal aspect provides protection against commercial, legal and medico legal litigation. It provides a practical implication of understanding the theoretical aspect of medical and dental history, chart notes, radiographs, photographs and models, because, legally, dentist written records carry more weight than the patient's recollections. ${ }^{30}$

\section{Conclusions}

Prosthodontic practice has evolved in terms of materials, instrumentations and modern technologies which has advanced the prosthetic treatments, while at the same time rendered professionals prone to diverse risks of occupational hazards. Although, prosthodontic practice will probably never be free of these threats and dangers, appropriate steps can be taken to minimize these problems. Most effective way to reduce effect of any chemical is to substitute it with a safer alternative. It is the responsibility of the prosthodontist and the team to understand the specific risks and formulate an effective management protocol. Universal precaution has to be taken during practice to prevent occupational hazards. Adoption of internationally accepted formulated guidelines will help in minimizing such hazards.

\section{References}

1. Babaji P, Samadi F, Jaiswal JN etal. Occupational hazards among dentists: a review of literature. J Int Dent Med Res 2011;4:87-93.

2. Tillberg A, Jarvholm B, Berglund A. Risks with dental materials. Dent Mater 2008;24:940-43. https://doi.org/10.1016/j.dental.2007.11.009

3. Siew C, Chang SB, Gruninger SE et al. Selfreported percutaneous injuries in dentists: Implications for HBV, HIV, transmission risk. J Am Dent Assoc 1992;123:36-44. https://doi. org/10.14219/jada.archive.1992.0149

4. Szymanska J. Dentist's hand symptoms and high-frequency vibration. Ann Agric Environ Med 2001; 8:7-10. PMID: 11426919

5. Farrier SL, Farrier JN, Gilmour AS. Eye safety in operative dentistry - a study in general dental practice. Br Dent J 2006;200:218-23. https:// doi.org/10.1038/sj.bdj.4813257

6. Chen E. Inhibition of cytochrome oxidase and blue-light damage in rat retina. Graefes Arch Clin Exp Ophthalmol 1993;231:416-23. https:// doi.org/10.1007/BF00919652 
7. OSHA. Department of Labor occupational noise exposure.1983; CFR29, 1910.95. [Accessed on sept 01, 2020 https://www.osha.gov/dts/osta/ otm/new noise/\#standards

8. St John KR. Biocompatibility of dental materials. Dent Clin North Am 2007;51:747-60. https://doi.org/10.1016/j.cden.2007.03.003

9. Morgenroth $\mathrm{K}$, Kronenberger $\mathrm{H}$, Michalke $\mathrm{G}$ et al. Morphology and pathogenesis of pneumoconiosis in dental technicians. Pathol Res Pract 1985;179:528-36. https://doi. org/10.1016/s0344-0338(85)80194-1

10. Haberman AL, Pratt M, Storrs FJ. Contact dermatitis from beryllium in dental alloys. Contact Dermatitis 1993;28:157-162. https:// doi.org/10.1111/j.1600-0536.1993.tb03378.x

11. Kim TS, Kim HA, Heo Y et al. Level of silica in the respirable dust inhaled by dental technicians with demonstration of respirable symptoms. Ind Health 2002;40:260-65. https://doi.org/10.2486/ indhealth. 40.260

12. Hamann CP, Rodgers PA, Sullivan KM. Occupational allergens in dentistry. Curr Opin Allergy Clin Immunol 2004;4:403-409. https:// doi.org/10.1097/00130832-200410000-00012

13. Choudat D. Occupational lung diseases among dental technicians. Tuber Lung Dis 1994;75:99-104. https://doi.org/10.1016/09628479(94)90037-x

14. Litovitz TL, Klein-Schwartz W, Dyer KS, Shannon $\mathrm{M}$ et al. Annual report of the American association of poison control centers toxic exposure surveillance system. Am J Emerg Med 1998;16:443-497. https://doi.org/10.1016/ s0735-6757(98)90000-6

15. Calamia JR. Clinical evaluation of etched porcelain veneers. Am J Dent 1989;2:9-15. PMID 2597374

16. Mc Donald RI, Walsh LJ, Savage NW. Analysis of workplace injuries in a dental school environment. Aust Dent J 1997;42:109-113. https://doi.org/10.1111/j.1834-7819.1997. tb00105.x

17. Nayebzadeh A, Dufresne A. Evaluation of exposure to methyl methacrylate among dental laboratoty technicians. Am Ind Hyg Assoc J 1999;60:625-628. https://doi. org/10.1080/00028899908984482
18. Leggat PA, Chowanadisai S, Kukiattrakoon B et al. Occupational hygiene practices of dentists in southern Thailand. Int Dent J 2001;51:1116. https://doi.org/10.1002/j.1875-595x.2001. tb00811.x

19. Kuroyanagi K, Hayakawa Y, Fujimori H et al. Distribution of scattered radiation during intraoral radiography with the patient in supine position. Oral Surg Oral Med Oral Pathol Oral Radiol Endod 1998; 85:736-41. https://doi. org/10.1016/s1079-2104(98)90044-0

20. Szymanska J. Dental bioaerosol as an occupational hazard in a dentist's workplace. Ann Agric Environ Med 2007;14:203-207. PMID: 18247451

21. Health and Safety Executive. Evaluating the protection afforded by surgical masks against influenza bioaerosols: Gross protection of surgical masks compared to filtering facepiece respirators. 2008. (accessed Sept 2020) Available at https://www.hse.gov.uk/research/ rrpdf/rr619.pdf

22. Dexter F, Parra MC, Brown JR et al. Perioperative COVID-19 defense: an evidence-based approach for optimization of infection control and operating room management. Anesth Analg 2020;131:37-42. PMID: 18247451

23. Jennings KJ, Samaranayake LP. The persistence of microorganisms on impression materials following disinfection. Int $\mathrm{J}$ Prosthodont 1991;4:382-387. PMID: 1811634

24. Bolyard EA, Tablan OC, Williams WW et al. Guideline for infection control in health care personnel. Hospital Infection Control Practices Advisory Committee. Am J Infect Control 1998;26:289-354. Available from: https://www. cdc.gov/hicpac/pdf/InfectControl98.pdf

25. Rutala WA, Weber DJ, Robert A. Weinstein RA, Pearson ML, Chinn RYW, DeMaria A et al,. Guideline for Disinfection and Sterilization in Healthcare Facilities, 2008. CDC updated 2019;1-163. Available from: https://www.cdc. gov/infectioncontrol/guidelines/disinfection/

26. OSHA. Bloodborne pathogens. 2018. eCFR29, 1910.1030(a). [Accessed on sept 17, 2020] Available from: https:// www.osha.gov/laws-regs/regulations/ standardnumber/1910/1910.1030 
27. Harutunian K, Gargallo-Albiol J, Figueiredo R et al. Ergonomics and musculoskeletal pain among postgraduate students and faculty members of the School of Dentistry of the University of Barcelona (Spain). A cross-sectional study. Med Oral Patol Oral Cir Bucal 2011;16:e425-e429. https://doi.org/10.4317/medoral.16.e425

28. Al Wazzan KA, Almas K, Al Shethri SE et al. Back and neck problems among dentists and dental auxiliaries. J Contemp Dent Pract 2001;2:17-30. PMID: 12167924

29. Ayers K, Thomson W, Newton JT et al. Job stressors of New Zealand dentists and their coping strategies. Occupational Medicine 2008; 58: 275-81. https://doi.org/10.1093/occmed/kqn014

30. Bhadauria PN, Dasar PL, Sandesh N et al. Medico-legal aspect of dental practice. Clujul Medical 2018;91:255-258. https://dx.doi. org/10.15386\%2Fcjmed-764 